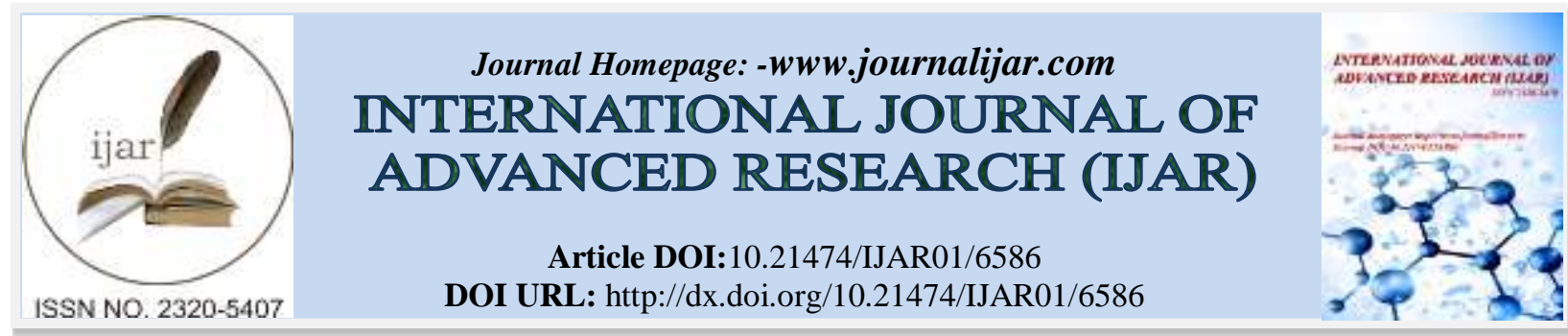

RESEARCH ARTICLE

\title{
PREVELANCE OF DOMESTIC INJURIES AND FIRST AID AWARENESS AMONG KUWAITS 18 OLD AND ABOVE.
}

\author{
Mohammad Qasem Ali, Dr.Tawfeeq Naseeb Fahad, Abdullah Al-Otaibi, JassimWajih Al-Qallaf, \\ MosaMardashti, ReemYousef Al-Ghanim, ZainabNaser Kamal, Ammar Ahmad Mohammad, \\ HananMajedSalmeen, Mahdi Khalid Al-Qallaf and Taiba Khalid Al-Sultan.
}

\section{Manuscript Info}

(.........................

Manuscript History

Received: 19 December 2017

Final Accepted: 21 January 2018

Published: February 2018

Keywords:-

Sponge, Levantine, Mediterranean, Antibacterial Agent, Pathogenic Bacteria.

\section{Abstract}

Injury is defined medically as being harm as a result of trauma; it is one of the most common problems that may face people in their daily life especially at home. Domestic injuries may sometimes be life-threating issue and in another situations they may also lead in the decrease of life expectancy in some cases due to the bad prognosis they represent.

First aid is the urgent medical care that is provided to the victim till further medical treatment and care arrives. Simply first aid knowledge provides skills and practice to give a required life support and develop safety habits in the population's life, therefore it is really important to have good knowledge about it and enough experience in it.

This study is a cross sectional study conducted in July and August 2013, study collection of data is done at shopping malls (Alkout, Sharq, Alfanar and Almobarkyya).), and study sample is 600 Kuwaitis aged from 18 years and above. Questionnaire is used as the data instrument (appendix 1 and 2). SPSS is used for analysis of the data and interpretation of the results.

This study is conducted to determine the prevalence of domestic injuries among Kuwaitis, know the most common injury in each particular age group, Asses awareness of first aid and know the best way to raise first aid knowledge.

The aim of this research is to raise the awareness of first aid in the Kuwaiti population, improve the Kuwaiti population abilities to deal with the most common domestic injuries.

The results of this research showed that the prevalence of domestic injuries is more than two third of the sample, Cut wounds represented the highest injury and electric shock was the lowest. There was variation on whether the response is right ${ }^{(12)}$ or wrong depending on the injury. There was also variation in the opinions of the participants on how to improve first aid knowledge, preferring it to be part of the school curriculum, taking it as practical courses or making television shows about it and not forgetting about the other opinions they shared. In conclusion this study shows that the prevalence of domestic injuries in the Kuwaiti population is high. More than half of the injuries dealt with by the responders in a correct way according to first aid instructions, which reflect somehow good level of awareness within the 
Kuwaiti population ,furthermore in Support to this statement, the majority believes in the importance of first aid kit and also it was found that they have first aid kit in their possession. The sources of their knowledge were obtained mainly from media, first aid courses and others. However, the majority of the sample believe that the best way of dissemination first aid knowledge is by making it part of the school curriculum. Finally, it can be concluded that there is a big chance for Kuwaitis to fill the missing gap in learning the most fundamental basic aspects of first aid.

Copy Right, IJAR, 2018,. All rights reserved.

\section{Introduction:-}

Injury is defined in the medical dictionary as a damage, harm, hurt, or loss of tissue, as a result of trauma. It can be classified depending on three criteria. The first criterion is the cause, which involves traumatic injury causing a body wound or shock produced by sudden physical injury from violence or accident, radiation, burn or frostbite and toxin or adverse effect of pharmaceutical drugs. The second criterion is the site of the injury in the body, which involves brain injury, spinal cord injury, nerve injury and soft tissue injury. The last criterion is the activity, which involves sport, occupation, accidents and domestic injuries.

First aid is an urgent medical care or treatment, which is provided to a victim who is in need of immediate assistance due to sudden illness or injury, before the arrival of an ambulance or any qualified professional medical help. It involves making decisions that will help the injured person until medical help arrives. First aid is a treatment given to a casualty in order to preserve life, prevent further injury, prevent worsening and deterioration of the condition, promote recovery and to make the victim as comfortable as possible. First aid education does not only provide knowledge and skills to give life support and other emergency care, but also helps people to develop safety awareness and habits to ensure safety whether at work, home, in the mall or even on the streets and highways. It is important to introduce first aid awareness to teach people to be calm, confident and to deliver first aid treatment at any medical situations.

This study concentrates on domestic injuries (indoor injuries), which are burns, fractures, electrical shocks and cuts, they are considered the second most common injuries, as the study that was conducted by WHO in Iraq to establish the most common cause of injury visiting the emergency room and it showed that domestic injuries were the second most common injuries following traffic accident injuries ${ }^{(1)}$. The study will provide information about prevalence of these injuries in Kuwait. Also due to the benefits of first aid that were mentioned earlier the study will provide information about the prevalence of first aid training institutes and Kuwaiti's knowledge on first aid, and if they have used it in their emergency situations. In conclusion the study describes the first aid delivered in domestic injuries among the Kuwaiti population and their awareness about the importance of first aid.

\section{Literature Review:-}

According to WHO the majority of unintentional injuries are in children and adolescents, they account for almost $85 \%$ of child injury deaths globally ${ }^{(2)}$. The injury rates and patterns differ from country to country, even within the same region, and also between urban to rural areas' The study sample consisted of 1559 child $\leq 12$ years of age who were seen in hospital emergency departments in four urban centers in developing countries. Of these children, 32\% were in Egypt, 28\% in Pakistan, 25\% in Bangladesh and 15\% in Colombia. Of the total of 1559 cases, 1010 (65\%) were male; $941(60 \%)$ were $\geq 5$ years of age, and $32(2 \%)$ were $<1$ year old. The observed injuries occurred throughout the day, $63 \%$ of injuries occurred mainly while children were at play, while only $7 \%$ took place during school or other activities ${ }^{(3)}$.

Domestic injuries are one of the most common unintentional injuries worldwide. In a study conducted by Adesh institute of Medical Sciences \& Researching, to study the frequency and type of domestic accidents, Accidents outside home i.e. at the place of work or at school and those which happen to be road traffic accidents were excluded from the study. The study was carried out in the village Saharan Majra. The entire population of the village consisting of 2825 individuals was studied for one year. It was found that incidence density of accident was 106.2/1000 person-years of observation. More accidents occurred in females (173) as compared to males (127). 
More than half were trivial followed by minor and serious accidents respectively. In their research they declared that Injury as a research problem has been largely ignored in developing countries ${ }^{(4)}$

A study of home injuries was carried out in emergency department at civil hospital in Italy to evaluate prevalence, characteristics and possible preventive actions. The distribution was calculated in relation to sex, age, month, and code of urgency, outcomes, type and location of trauma. Results showed that children, men between 30-40 years and women over 60 years are the population at risk for the domestic injuries. With a fairly homogeneous incidence distribution. Both sexes have similar distributions up to 41-50 years followed by an increase in females and a decrease in males at higher age. The traumas are generally slight (49.8\% white code and $42.1 \%$ green code) and the hospitalizations represent $5.8 \%$ of all recorded home injuries. The most frequent injuries are wounds/abrasions (28.7\%), contusions/crushing (27.7\%) and fractures/distortions/ dislocations. The most affected body parts are hands and wrists $(25.9 \%)$. Head trauma is significantly more frequent in children and elderly people, fracture in elderly people, and burn in adult women and male children. Every year about $30 \%$ of the admissions to emergency departments are caused by home injuries. Even though $92 \%$ of the times the events were not serious, the sanitary cost is constant due to the greater number of admissions. It is therefore important to do prevention through sanitary education and adequate building legislation. ${ }^{(5)}$

A survey study in Qalubeya governorate, Injuries to children arising from home accidents are an increasing community health concern to that region. The aim of this cross-sectional study in Qalubeya governorate Egypt was to measure the incidence and types of home injuries affecting rural children aged up to 12 years and to assess their mothers' knowledge for dealing with these injuries, attitudes and practices (KAP) about first aid and its associated factors. 1450 rural mothers completed an interview questionnaire. The incidence of home injuries in the previous 4 weeks was $38.3 \%$ (57.5\% were boys). Cut wounds, falls and fractures, burns, poisoning and foreign body aspiration were the common forms of home injuries. Mothers answered an average of 11.0 (SD 5.3) out of 29 KAP questions correctly. Younger age of mother, higher level of education, higher socioeconomic status, being in paid employment, source of knowledge about first aid and having attended a training course on first aid were significant predictors of better KAP among mothers ${ }^{(6)}$.

As for first aid awareness number of researches and surveys were conducted in different countries on the importance of first aid procedures to provide basic life support until professional medical service arrives.

A research in Greece was conducted by nursing department of technological educational institute, among industry workers, the Aim of their study was to evaluate the knowledge on First Aid of industry workers through a questionnaire. Their sample constituted of 236 workers. 40 (Group A) were trained on first aid by a team of doctors authorized by the Hellenic National Centre of Emergency Help, while 196 had never have a formal training on first aid (Group B). In Group A the mean value of correct answers (performance score) was higher than Group B (62.7 and 50.4 respectively), while the total sample of workers ranged from 21.1 to 84.2. Also testing their vital signs measuring skills, Group a replied correctly about normal values (NVs) of pulse, arterial blood pressure (BP) and breaths at $67.5 \%, 35 \%$ and $47.5 \%$ respectively. Group B replied at 32.8\%, $18.4 \%$ and $30.6 \%$ on the corresponding NVs. In Group A, 95\% answered properly about the definition of Cardiopulmonary Rehabilitation (CPR) but only $25 \%$ were acquaint with the necessary number of chest compressions and $32.5 \%$ with the number of necessary mouth- to-mouth ventilations to practice in case of CPR. In Group B, the corresponding percentages were $72.4 \%$, $26 \%$ and $36.7 \%$. Only 5\% from Group A and 1\% from Group B answer correctly and simultaneously about estimation of vital signs and CPR practice. In conclusion, the vast majority of workers are unable to provide efficient first aid as long as they can't estimate vital signs and provide satisfactory CPR. ${ }^{(7)}$.

Another study took place in the United States of America. Following the American academy of pediatrics has publication of simple guidelines for managing children's injuries. The study aim was to evaluate the effectiveness of these guidelines among parents, knowledge of specific guidelines ranged from $21 \%$ to $92 \%$. Result showed that only $21 \%$ were aware about keeping wounds moist and covered, $43 \%$ were aware about the need to cover victims with large burns, and $47 \%$ were aware about the need to seek medical attention after tick bites. They concluded that $34 \%$ of the adults are unfamiliar with first aid measures ${ }^{(8)}$.

Many efforts worldwide were done to raise the level of first aid awareness by encouraging people to participate in training courses and by assessing the already trained population to determine the amount of avoidable injuries and its complications. In the United Kingdom, a study conducted by health and safety laboratory, to determine the 
number of first aid trainees in three years period in the United Kingdom, the results showed that people who had first aid certificates was nearly 25\% in the first year, 35\% in the second year and $40 \%$ in the third year, this indicates that people awareness about the importance of first aid is rising every year ${ }^{(9)}$.

Another study conducted by St. John ambulance institution in the United Kingdom for domestic injuries shows that the majority does not know the correct practice for treating a nosebleed (59\%) or someone who has fainted (57\%). This is particularly worrying in light of the fact that almost 4,000 people in the United Kingdom die in accidents in the home every year ${ }^{(10)}$.

Also According to a new survey commissioned by Target Company, almost one-quarter of Western Canadians (22 $\%)$ do not have a first aid kit at home, and the majority (60\%) reported not having a first aid kit in their car. The survey also found 58 per cent of people without first aid kits believe that they have first aid essentials in various locations throughout their home. However, Target pharmacists believe clearly marked first-aid kits are critical to ensure proper steps are performed when treating injuries. Pharmacists propose families place first aid kits in easily identifiable and accessible areas in the home and car. The survey also found that Western Canadians are missing many of the first aid essentials from their personal kits. Although those with first aid kits have common items such as adhesive bandages ( 91 per cent), sterile gauze pads ( 87 per cent), and adhesive tape ( 85 percent), many people tend to forget about non-medical supplies that should be included such as emergency telephone numbers (22 per cent), a pencil and pad ( 29 per cent), instant ice packs ( 32 per cent) and a flashlight with extra batteries ( 35 per cent) (11)

\section{Study Aim:-}

1. To raise awareness of first aid among Kuwaiti population.

2. To improve the Kuwaiti population abilities in dealing with the most common domestic injuries.

\section{Study Objectives :-}

Primary Objectives:-

1. To determine the prevalence of domestic injuries among the Kuwaiti population

2. To know the most common domestic injury within every age group.

3. To assess the awareness of First Aid among Kuwaiti's aged 18 years and above.

\section{Secondary objectives:-}

1. To take the participants' opinions about the best way of delivering first aid knowledge.

2. To know the most common way in gaining first aid knowledge among the population.

3. To assess the responses to domestic injuries using first Aid logbook.

\section{Methods:-}

1. Type of study: Cross sectional study was considered in this research.

2. Data sources/Collection: The source was from four Kuwaiti shopping malls (Alkout, Sharq, Alfanar and Almobarkyya). Random sample was taken from the malls that were mentioned previously.

3. Time of collection: The data collection took place during summer, July \& August 2013

4. Population/sample size: The population was the Kuwaiti population in the malls. The sample size was a convenient sample of 600 Kuwaiti aged from 18 \& above.

5. Study instrument: A questionnaire (Appendix 1 and 2) was used to collect the data \& participants were asked to fill it up.

6. Pilot study: A pilot study was done in Kuwait in March 2013 to find if there are any difficulties in filling the questionnaire.

7. Data analysis: The data was analyzed using SPSS program version 20.0, for mac laptop. The results that were ended up with showed the frequencies, numbers \& schedules were needed to calculate the prevalence of domestic injuries and to assess the First Aid knowledge.

\section{Results:-}

In this study the sample was about 600 people males and females. 
Table 1:- the education level of the responders

\begin{tabular}{|l|l|}
\hline Education level & Responders \% \\
\hline Not educated & $0.7 \%$ \\
\hline Elementary school & $0.8 \%$ \\
\hline Primary school & $3.7 \%$ \\
\hline Secondary school & $24.4 \%$ \\
\hline Further education & $69.8 \%$ \\
\hline
\end{tabular}

From this table (Table 1), it is noticed that most of the responders had further education.

Table 2:- Occupation of the responders

\begin{tabular}{|l|l|}
\hline Occupation & Responders \% \\
\hline Not in the medical field & $50 \%$ \\
\hline Student & $23.5 \%$ \\
\hline Not employed & $16.5 \%$ \\
\hline In the medical field & $9 \%$ \\
\hline
\end{tabular}

Regarding occupation, half of the sample (Exactly 50\%) were not medical workers, while only $9 \%$ were from the medical field, $23.5 \%$ were students and $16.5 \%$ were without a work.

The results showed that $76.2 \%$ of the sample suffered from domestic injuries, $46.3 \%$ of responders were males and $53.5 \%$ were females. Concerning the age distribution the majority were between ( $18-37$ years), and the least were $>58$ years.

Cuts represented the highest percentage of domestic injuries (36.1\%) followed by burns $(30.1 \%)$, fracture (21.6\%), choking (9.6\%) and electrical shock (2.6\%). Most people who got injured were ranging between (0-19). Each particular age group has its own most common injury, being highest as following: burns (20-29), fractures (10-19), cuts (0-9), chocking (0-9) and electric shock (10-19).

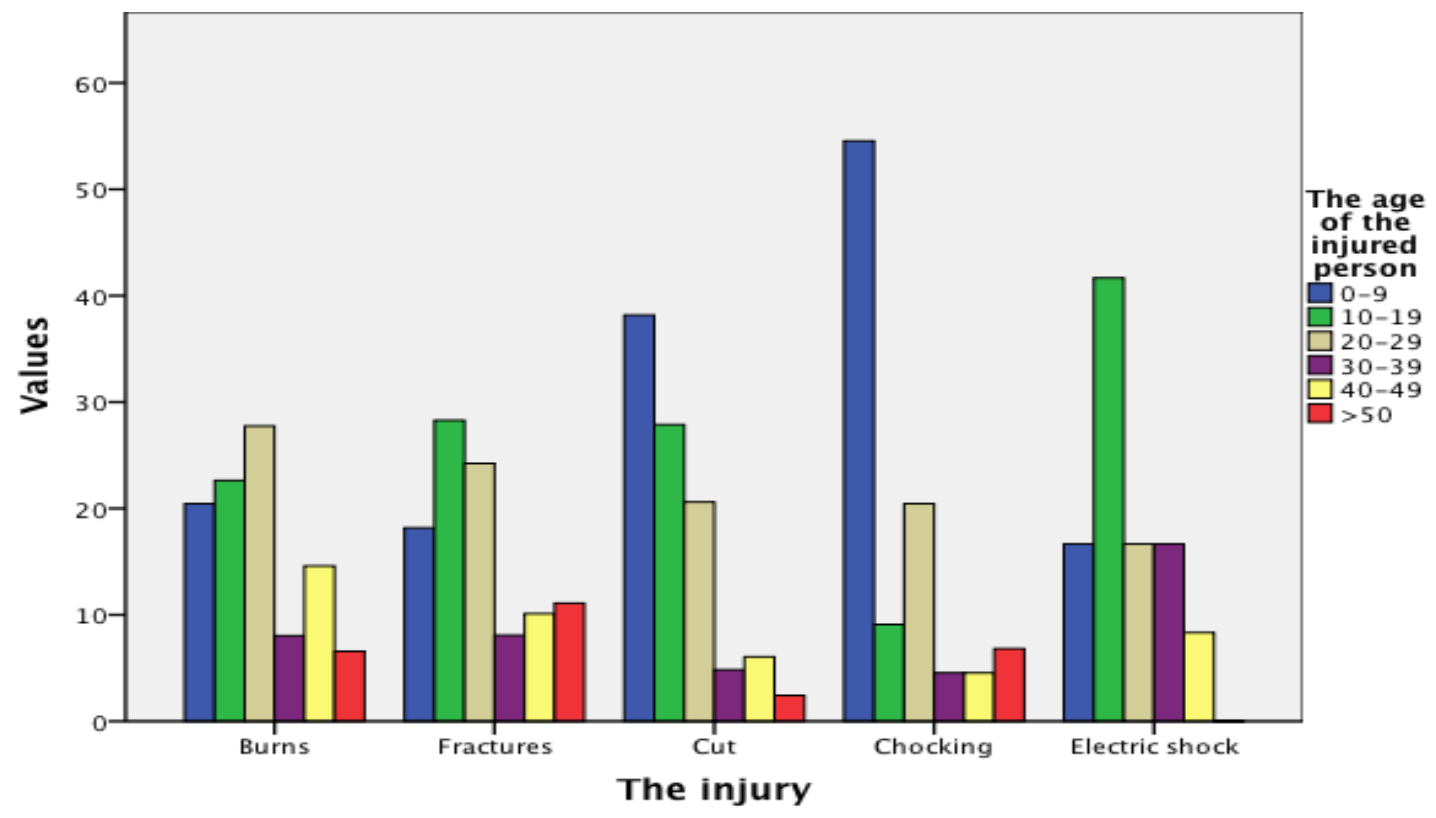

The age of the injured person of every injury 
Table 3:- The right response (What is meant by a right response, that the instructions of first aid is followed) ${ }^{(12)}$ to specific injuries

\begin{tabular}{|l|l|}
\hline The injury & Right response \\
\hline Cut & $67.9 \%$ \\
\hline Burns & $60.6 \%$ \\
\hline Chocking & $45.5 \%$ \\
\hline Electric Shock & $33.3 \%$ \\
\hline Fractures & $22.2 \%$ \\
\hline
\end{tabular}

Overall in the sample studied, the right responses that were delivered to the injured persons were $52.7 \%$. The table above (Table 3), if every injury is taken separately it is seen that cuts and burns had the highest rate of right response (67.9\% and $60.6 \%$ respectively). It is an indication that these two injuries are the most injuries that contributed in the percentage of the right response.

Table 4:- The response assessment within the ones who went to the hospital

\begin{tabular}{|l|l|}
\hline Response assessment of those who went to the hospital & Percentages \\
\hline Right response & $22.7 \%$ \\
\hline Wrong response & $77.3 \%$ \\
\hline
\end{tabular}

In this study it is seen that the ones who went to the hospital are 33.7\%. From the table above (table 4), it is seen that from those who went to the hospital , $77.3 \%$ dealt with the injury in a wrong way and $22.7 \%$ dealt with the injury in a right way.

It was interesting to find out that $71.1 \%$ of the responders knew the correct emergency number, and most of them were educated. From the sample 55\% tried to interfere with the injury, which leaves $45 \%$ didn't interfere and $42.4 \%$ of them (From the $45 \%$ that did not interfere) did not interfere because they did not trust their ability, meanwhile $25.9 \%$ (from the $45 \%$ that did not interfere) of them are not willing to interfere because they think there is always someone else who is better than them and $26.6 \%$ (From the $45 \%$ that did not interfere) of them did not face any injury to interfere with in the first place. The rest of them (5.2\%) (From the 45\% that did not interfere) they did not care about the injury that took place in front of them.

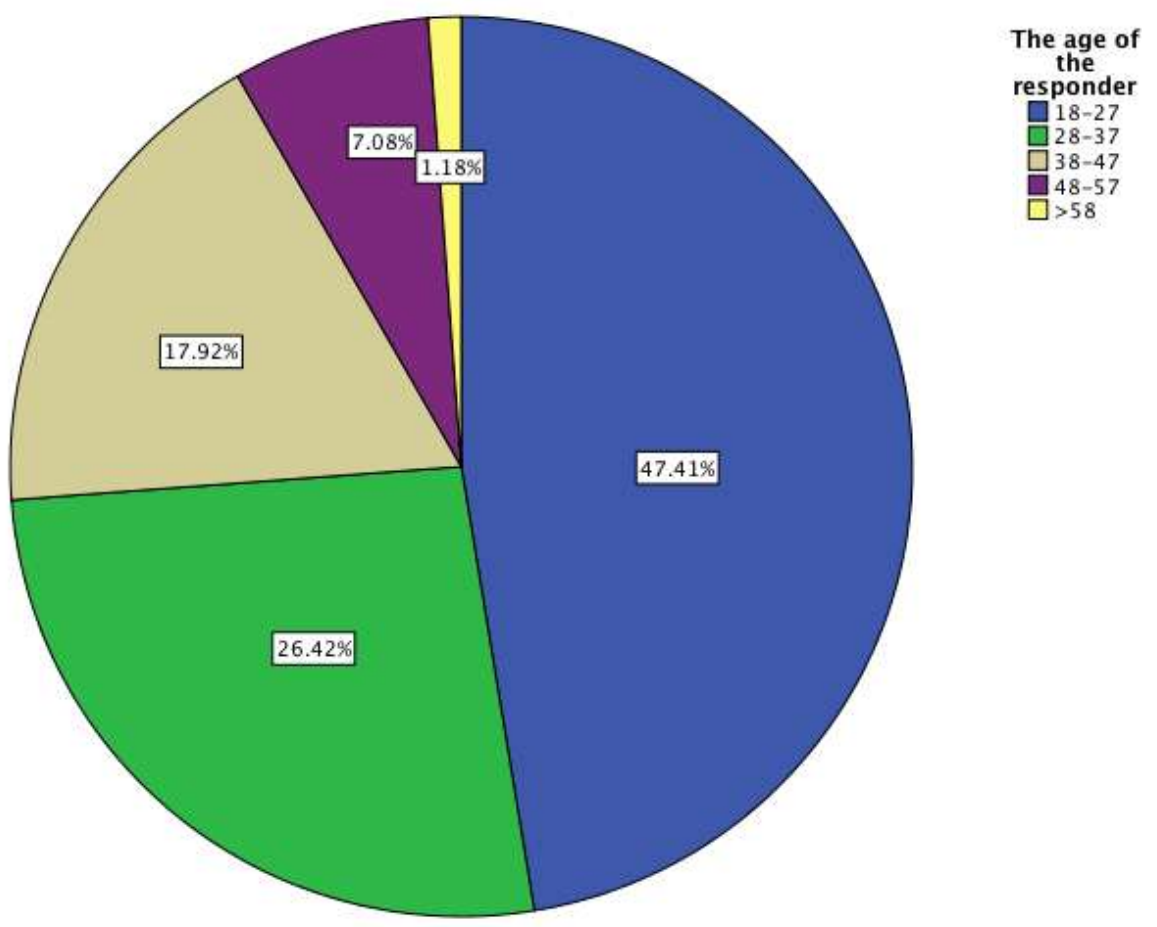

The age of the responder within the ones who know the emergency number

Most people who knew the emergency number were at the age group of 18-27 (47.41\%) followed by ages between $28-37(26.42 \%), 38-47(17.92 \%), 48-57(7.08 \%)$ and lastly $>58(1.18 \%)$. 
Table 5:- the right response ${ }^{(12)}$ and the emergency number and the occupation

\begin{tabular}{|l|l|l|}
\hline The occupation & Right response $\%$ & Knowing emergency number \\
\hline In the medical field & $70.2 \%$ & $81.5 \%$ \\
\hline Not in the medical field & $49.4 \%$ & $71.6 \%$ \\
\hline Unemployed & $57.7 \%$ & $59.2 \%$ \\
\hline Student & $48.9 \%$ & $74.8 \%$ \\
\hline
\end{tabular}

The study revealed that the percentage of the right response (What is meant by a right response, that the instructions of first aid is followed) ${ }^{(12)}$ was the highest $(70.2 \%)$ among the responders in medical field, comparing it with other categories, and to knowing the emergency number $(81.5 \%)$, comparing it with the other categories. The percentage was around half to $3 \backslash 4$ of their number concerning the knowledge of emergency number, ranging from $59.2 \%$ to $74.8 \%$, among the rest of the categories. It was also ranging from $48.9 \%$ to $57.7 \%$ among the rest of the categories concerning the right response ${ }^{(12)}$ to injuries.

First aid procedure is completed with the first aid kit, it was shown that $92.3 \%$ of the sample thought that owning a first aid kit is very important and $58.8 \%$ had the kit and most of young people tend to have the first aid kits.

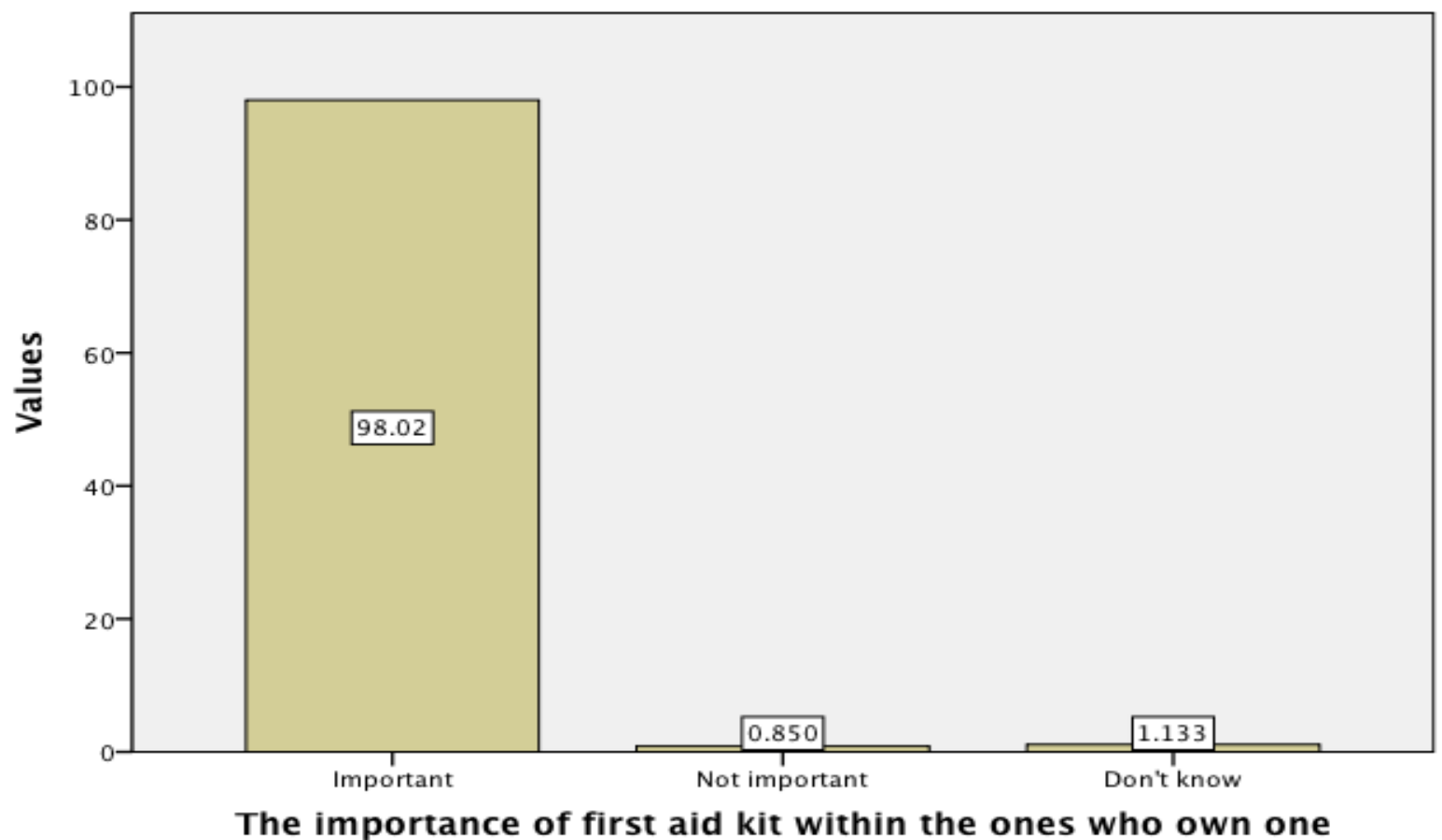

This graphs explains that $98.02 \%$ among those who own a kit $(58.9 \%)$ believe about the importance of having it.

Most sources of knowledge were taken from media (Television, Radio, Internet \& social networks, Newspapers and magazines) (48.2\%) followed by advices and instructions taken from someone in the medical field or someone who had first aid course, in a percentage varying between $(10.2 \%-16.3 \%)$ 


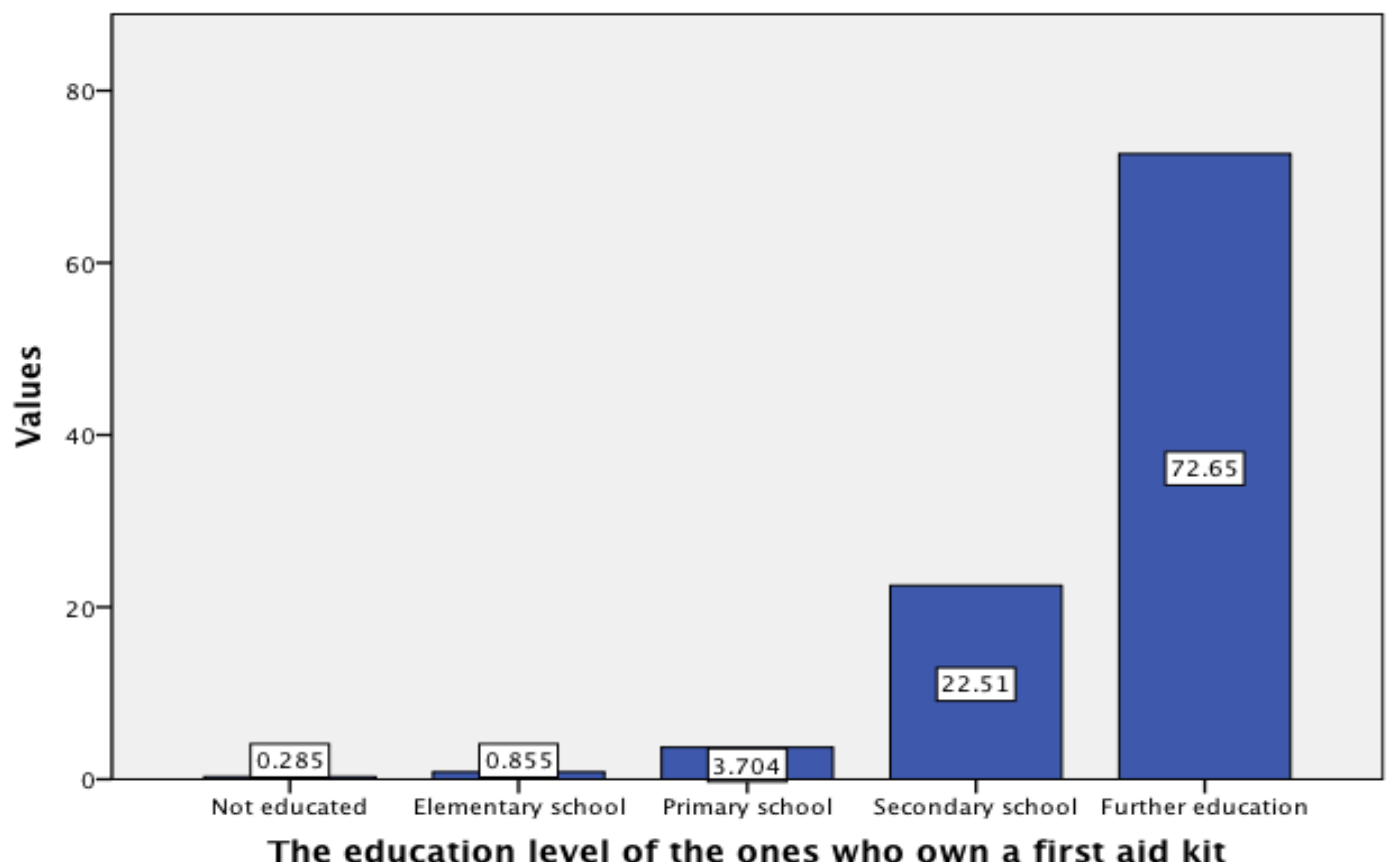

As shown in the figure above, it is seen that more than the half (72.65\%) of the educated people, who had further education, in the sample had a first aid kit. It is also concluded from the figure that the more the individuals are educated the more tended they are to possess a first aid kit.

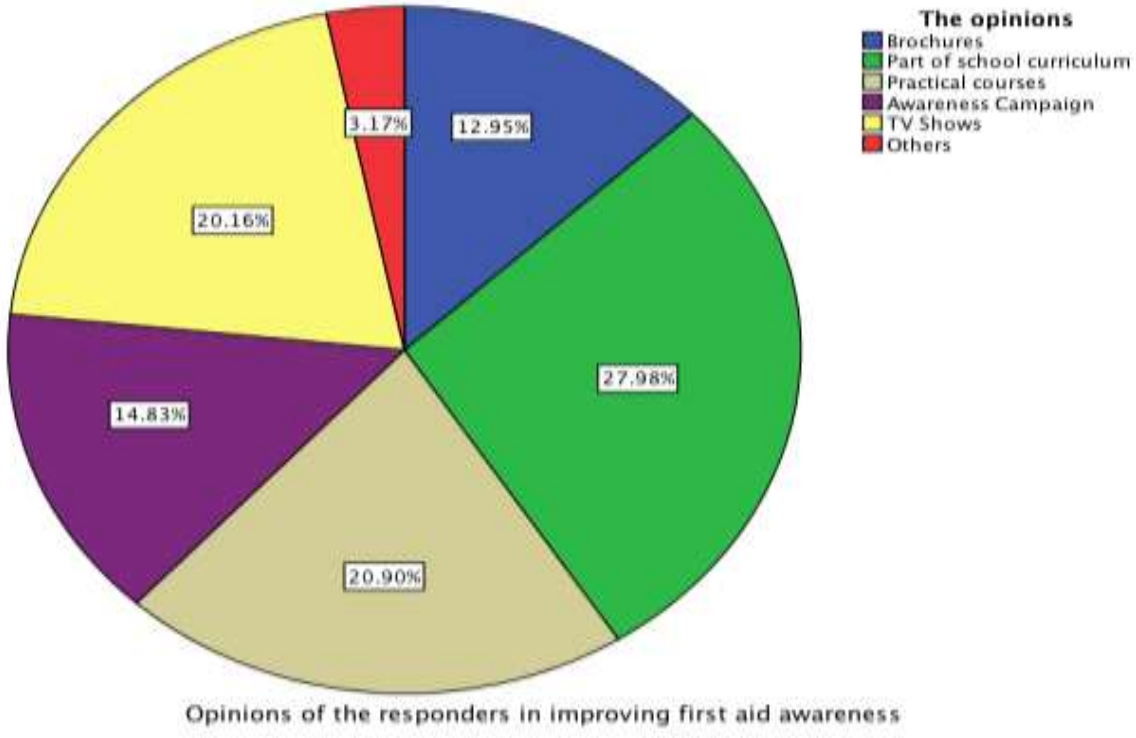

The figure shown above, shows opinions of the responders on how to improve first aid awareness, $27.9 \%$ chose to make it part of school curriculum followed by taking practical course (20.9\%) and television shows (20.26\%). They were also followed by, as shown in the figure above, awareness campaign (14.83\%), distributing brochures $(12.95 \%)$ and others $(3.27 \%)$. In the choice "others" it was required from the responder to write other opinions, which there was a space provided for them in the appendix 1 or 2 . Most of them, who chose others as a choice, wrote in the space social networks, such as instagram, twitter, whatsapp and Facebook. 

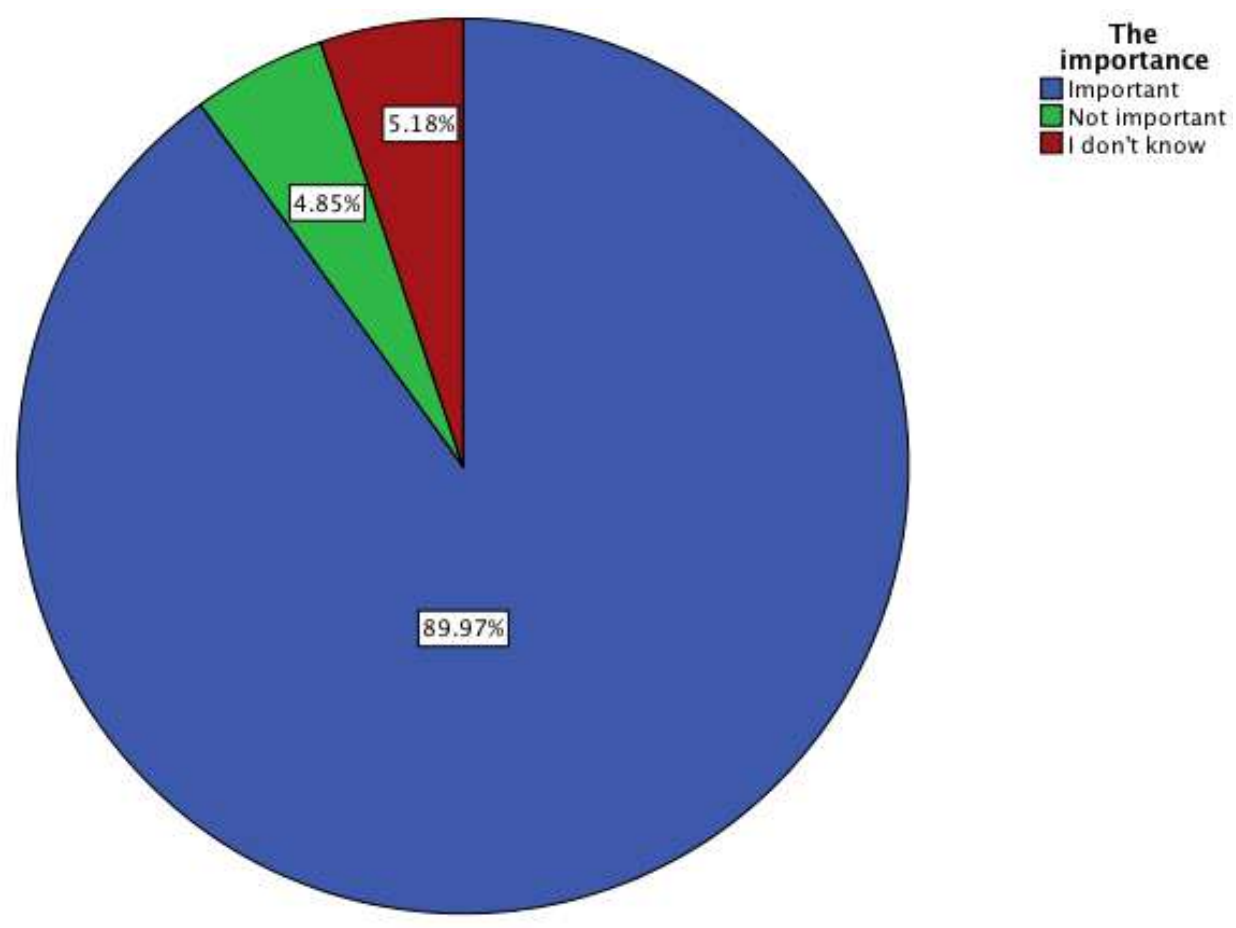

Opinions of the responders in first aid awareness

Figure 5 shows that the majority $(89.97 \%)$ considers first aid is an important topic to be learnt and gained, while $10.03 \%$ either consider first aid as a not important subject or have no opinion about it.

Table 6:- Shows the outcome of the responder's interference, if it was beneficial or not

\begin{tabular}{|c|c|}
\hline The outcome & Percentage \\
\hline Beneficial & $74.8 \%$ \\
\hline Not Beneficial & $9.6 \%$ \\
\hline Anonymous & $15.5 \%$ \\
\hline
\end{tabular}

According to the responders view on the response they made dealing with the injuries they faced, the table which is shown above $74.8 \%$ were beneficial, $9.6 \%$ weren't beneficial and $15.5 \%$ were anonymous. This view was based on the outcome of the signs and symptoms, mainly relief of pain. 


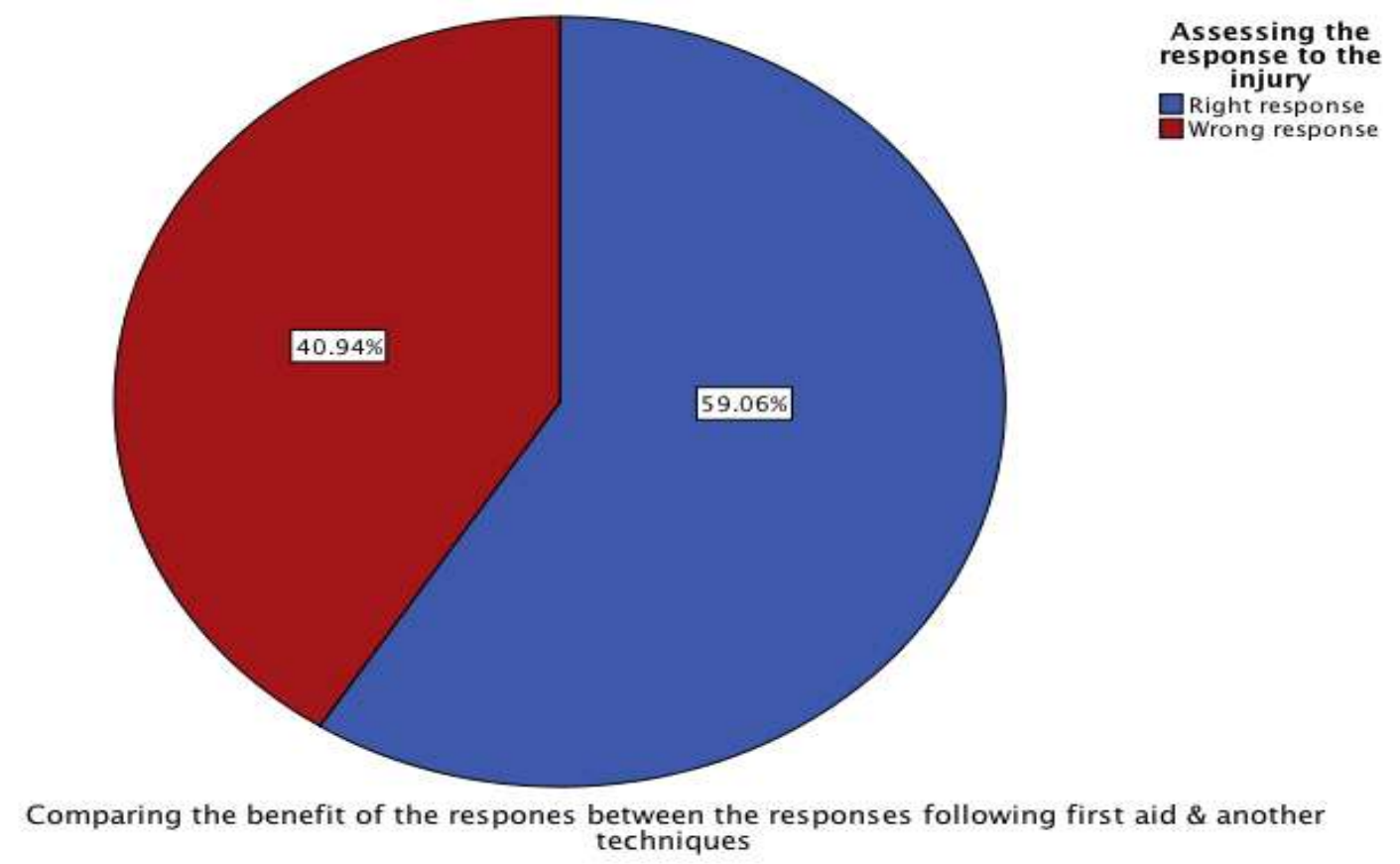

In the figure shown above, it is seen that if there is a comparison between the techniques of first aid and other ways (Cultural and environmental ways) followed to respond to an injury, first aid is more beneficial (59.06\%) than the other techniques (Cultural and environmental ways) (40.94\%). As mentioned above these benefits depends on the view of the responder on relief of the signs and symptoms, mainly pain.

Table 7:- The spread of knowledge from the responders

\begin{tabular}{|l|l|}
\hline The spread of knowledge & Percentages \\
\hline They do spread the knowledge & $23.5 \%$ \\
\hline They don't spread it & $39.3 \%$ \\
\hline They sometimes do & $37.2 \%$ \\
\hline
\end{tabular}

Here in the above table it is shown that the ones who really do spread the knowledge about the way of dealing with injuries are $23.5 \%$ and the ones who do not spread the knowledge about dealing with injuries are $39.3 \%$. Meanwhile, $37.2 \%$ they sometimes do depending on the situation and the people they are surrounded with.

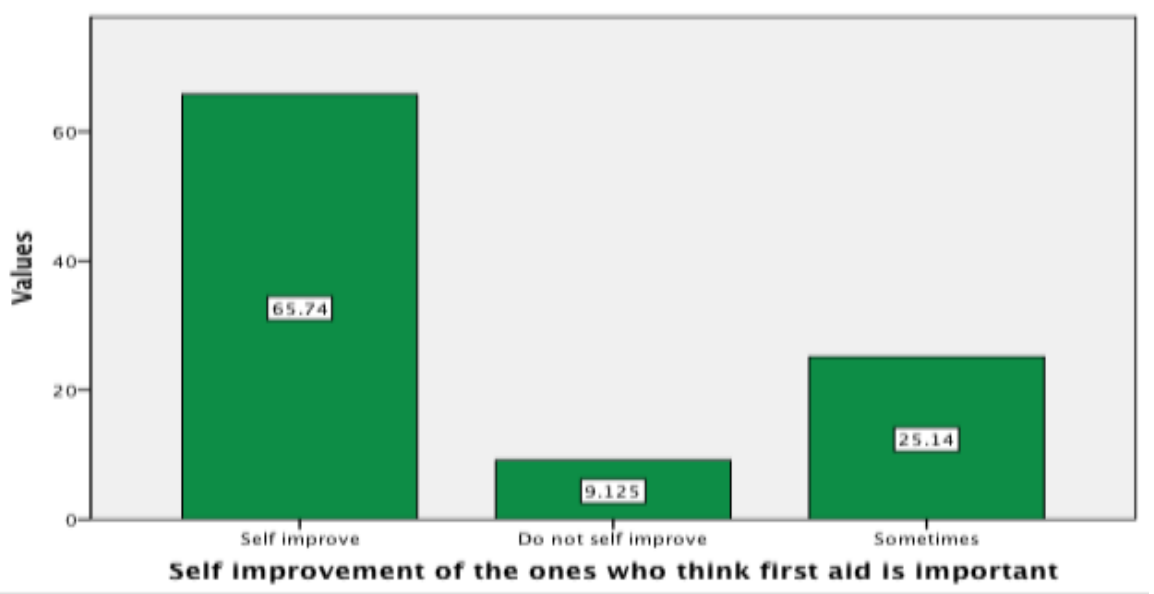

In the figure that is shown above, it is noticed that those who believe in the importance of first aid and they really work for self improvement are $65.74 \%$. On the other hand, the ones who believe in the importance of first aid but 
and do not work for or themselves were $9.125 \%$. Meanwhile, there were those who sometimes find the time and sometimes improve themselves while believing in its importance are $25.14 \%$.

Table 8:- The responder's knowledge of first courses that are held in Kuwait

\begin{tabular}{|l|l|}
\hline The status of knowledge about Kuwait courses & Percentages \\
\hline Know about a course that is held in Kuwait & $18.7 \%$ \\
\hline Do not know about a course that is held in Kuwait & $81.3 \%$ \\
\hline
\end{tabular}

In the table above it is seen that only $18.7 \%$ know about a course that is held in Kuwait. There was a space to write the names of these courses, the courses that are known by the $18.7 \%$ of the sample are courses that are held by the Kuwaiti Red Crescent Center, Ministry of defense, ministry of Oil and Desman health center. Meanwhile, $81.3 \%$ of the sample did not have any idea about any courses of first aid that are held in Kuwait.

\section{Discussion:-}

The research shows that the prevalence of domestic injuries among the sample was $76.2 \%$, Cuts are the most common injury followed by burns, which correlate with the Italian study conducted in the emergency department civil hospital. It also shows that children in the age groups 0-9 years as well as the age group 10-29 years of the population had the most frequent injuries. This age group is considered most active where children are more exposed to cuts and chocking incidents, while young adults were found having more fractures, electric shocks and burns, similar results were found by the WHO study conducted in that matter.

The majority of the study sample had the right response in dealing with the injury following the first aid guidelines (12) which gives a good indication of the awareness level among the sample population, when comparing it with the study conducted by St. John ambulance institution in the United Kingdom for domestic injuries, which showed that the majority doesn't know the correct practice for treating home injuries like nosebleed or someone who has fainted.

In addition, seven out of ten people knew the emergency number in the study sample, which is satisfactory and relatively good. In comparison with the Canadian study, which stated that three quarters of their sample had the first aid kit, in this study shows that more than half of the sample had the first aid kit, which is relatively good, in addition; more than three quarters of the sampled population believe in the importance of having a kit at home.

Moreover, the good awareness of the population has been reflected by the fact that the majority of them knew the emergency number.

Not surprisingly the results show that the responders from the medical field had the highest rate of right response in dealing with injuries followed by the unemployed responders.

In this study it was found that the media (Television, Radio, Internet \& social networks, Newspapers and magazines) was the first source of knowledge for first aid knowledge, however, almost one third of the population see that introducing first aid skills in school curriculum would be the best way to increase awareness about it, followed by practicing it in practical courses and broadcasting it in television shows was the third choice.

It is also shown from the results that education has a very big role in the awareness of first aid, for example as we saw in the results that the higher educational level the increase the possibility of possessing a first aid kit. It is also noticed that the majority of the sample considered first aid is an important aspect that should be learnt and gained through out life.

If comparison is made between the responses in dealing with injuries, It will show that those who followed the instructions of first aid had a more beneficial effect in relieving the severity of the signs and symptoms of the injury. The main symptom that is relieved and was considered that the response was beneficial was pain, on the responders view. So we can conclude from this that first aid instructions are beneficial in dealing with injuries that may be faced at home, work or anywhere.

\section{Conclusion and Recommendations:-}

Domestic injuries are high in the community and more than half of the sample dealt with some of these injuries in the right way according to the first aid instructions ${ }^{(12) .}$ There is a good opportunity to improve people performance in providing first aid services to the injured victims aiming at increasing their numbers and ability to deal with all types of domestic injuries. An important recommendation from this research is to raise awareness of first aid among 
Kuwaiti population by several ways such as: educational television shows, programs and attractive advertisements, training courses and making first aid an important part of school curriculum based on the finding that the main source of first aid knowledge was the media. Moreover, increase the abilities of Kuwaitis to deal with different types of domestic injuries in the right way through practical role play courses. The study found out that more than half of the sample own first aid kit and of those $98 \%$ believed that in addition to having the First Aid Kit at home and car, they believe in its importance, therefore a lot can be done to encourage the community to have first aid kit through health education.

As this study showed that high number of Kuwaiti population are aware regarding first aid whether on dealing with injury or realizing the importance of its skills and seeking to improve it, there is a big chance to increase the number of Kuwaitis who have the fundamental basic aspects of first aid.

\section{References:-}

1. WHO EMRO Iraq (2008), Injury Surveillance Pilot Project, Iraq. Retrieve data at http://www.emro.who.int/irq/programmes/injury-surveillance.html

2. WHO - Children Environmental Health - Injuries - Risks (2013): Retrieve data at http://www.who.int/ceh/risks/cehinjuries/en/

3. WHO - Children Environmental Health - Injuries - Risks (2013): Retrieve data at http://www.who.int/ceh/risks/cehinjuries2/en/index.html

4. R. Aggwarl, G. Singh, and K. Aditya: Pattern of Domestic Injuries In A Rural Area Of India. The Internal Journal of Health. 2010; 11 (2). DOI: 10.5580/1d1f

5. S. Majori, G. Ricci, F. Capretta, G. Rocca, T. Baldovin, and F. Buonocore: Epidemiology of domestic injuries. A survey in an Emergency Department in Northeast Italy. University of Padua, Italy. J PREV MEDHYG, 2009 Jun; 50:164-169.

6. Eldosoky. R.S. Home-related injuries among children: knowledge, attitudes and practice about first aid among rural mothers. Department of community medicine Faculty of Medicine. University of Benha, Benha, Egypt. 2011 Nov; 18 (10): 1021-1027.

7. Hatzakis. KD, Kritsotakis. EI, Angelaki. HP, Tzanoudaki. IK, Androulaki. ZD. First Aid Knowledge among Industry Workers in Greece. Nursing Department of Technological Educational Institute of Crete, 54 Ieroloxitonstr, 71305 Heraklion, and Crete, Greece. US National Library of Medicine, National Institutes of Health. 2005 Feb; 43:327-332.

8. Singer. Adam. J, Gulla. Janet. RN, Thode. Henry. C. Parents and practitioners Are Poor Judges of Young Children's Pain Severity. Society for Academic Emergency Medicine. 2002 Jun; 9(6): 609-612.

9. Evans. G. HSE Survey of First Aid Training Organizations. Health \& Safety Laboratory, Harpur Hill, Buxton. Health \& Safety Executive. 2005:1-23.

10. St. john ambulance (news of 2009) $27 \mathrm{St}$ John's Lane, London EC1M 4BU: Retrieve data http://www.sja.org.uk/sja/about-us/latest-news/news-archive/news-stories-from-2009/february/national-firstaid-awareness.aspx

11. Target - press-releases - target finds many western Canadians lack first aid kit-2013: retrieve data at http://pressroom.target.com/news/target-study-finds-many-western-canadians-lack-first-aid-kits

12. Fawzi Abdullah Ameen, Faisal Almosawi, Abduljalil Alkohaji. First Aid program. Bahrain Red Crescent society. 2009; 4: 1-37. 